\title{
ANALISIS KELAYAKAN USAHATANI TOMAT (Solanum lycopersicum) DI KELURAHAN LANDASAN ULIN UTARA KECAMATAN LIANG ANGGANG KOTA BANJARBARU PROVINSI KALIMANTAN SELATAN
}

\section{(The Feasibility Analysis of Tomato Farming (Solanum lycopersicum) in Landasan Ulin Utara Liang Anggang Subdistrict Banjarbaru City South Kalimantan Province)}

\author{
Fitri Mahyudi ${ }^{1}$, dan Husinsyah ${ }^{1}$ \\ ${ }^{1}$ Program Studi Agribisnis Fakultas Pertanian Universitas Achmad Yani Banjarmasin \\ Coresponden author :fitri.mahyudi@yahoo.co.id
}

Article Submitted : 16-06-2019

Article Accepted : 02-10-2019

\begin{abstract}
This Research aim to know technically about effort management tomato farming evaluated from technical aspect in Landasan Ulin Utara Liang Anggang Subdistrict Banjarbaru City South Kalimantan Province and to know about cost, acceptance, revenue and tomato farming Feasibility. Pursuant to result of seen from technical management tomato farming still relative modestly, this seen from farm processing until the conservancy. Production obtained from 15 tomato farmer responder with wide mean equal to $352.236,45 \mathrm{~kg}$ / farmer. Productivity $16.670,62$ $\mathrm{kg} / \mathrm{ha}$ or 16,6 ton/ha. Total Revenue with mean Rp. 93.929.720 per farmer . Total Earnings mean Rp. 49.463.569,44 per farmer. RCR Value tomato farming 1.78 competent so that to be feasible $(\mathrm{RCR}>1)$.
\end{abstract}

Key words : Tomato, Price, Cost, Revenue, Feasibility Analysis

\section{PENDAHULUAN}

Tanaman hortikultura mempunyai kedudukan yang sangat penting dalam kehidupan masyarakat maupun perekonomian Negara. Dalam kehidupan masyarakat, peranannya sebagai sumber gizi. Sedangkan dalam perekonomian mempunyai nilai ekonomis yang tinggi dilihat dari sumberdaya terhadap peningkatan Devisa Negara (Patricia, 2001).

Komoditas Horitikultura merupakan komoditas yang dikonsumsi setiap hari, sehingga perlu untuk dikembangkan. Perlu dikembangkannya komoditas-komoditas Hortikultura karena komoditas ini memiliki nilai Ekonomis yang tinggi seperti halnya pada tomatmaka apabila dikembangkan dalam suatu sistem usahatani yang komersial dapat meningkatkan pendapatan petani.Pertumbuhan tomat tidak mengenal musim, sehingga mudah diperoleh setiap saat (Suratiyah, 2006). Varietas atau jenisnya juga cukup banyak. Keanekaragaman varietas tersebut diperoleh melalui kegiatan pemuliaan tanaman. Dengan pemuliaan tanaman,dihasilkan banyak varietas yang memiliki keunggulan, seperti tahan terhadap hama dan penyakit tertentu atau tahan terhadap cuaca atau lingkungan yang tidak mendukung (Soenoeadji, 2001).

Tanaman tomat, berasal dari daerah Peru dan Ekuador, kemudian menyebar ke seluruh Amerika, terutama ke wilayah yang beriklim tropik. Bangsa Eropa dan Asia mengenal tanaman tomat pada tahun 1523 . Namun pada waktu itu tanaman tomat dianggap sebagai tanaman beracun. dan hanya ditanam sebagai tanaman hias dan obat kanker. Tanaman tomat di tanam di 
Indonesia sesudah kedatangan orang Belanda, hal ini menandakan bahwa tanaman tomat sudah tersebar di seluruh dunia, baik di daerah tropik maupun subtropik (Cahyono, 1998).

Di sisi lain, pemuliaan tanaman juga bisa menghasilkan varietas tomat yang memiliki produktivitas tinggi. Tomat bisa dimanfaatkan dalam keadaan segar maupun diolah terlebih dahulu. Dalam keadaan segar tomat bisa sebagai sayuran, bumbu masak, ataupun sari buah. Jika diolah tomat bisa jadi saus, bahan kosmetik. (Wiryanta, 2002)

Untuk komoditi yang banyak diusahakan adalah tanaman tomat dengan mengunakan varietas tantina. Petani diKelurahan Landasan Ulin Utara tergolong petani tradisional dan masih menggunakan alat-alat yang sederhana, dan petani belum bisa memperhitungkan mengenai biaya yang dikeluarkan, sehingga petani tidak dapat menaikkan pendapatan keluarga.

Permasalahan yang dihadapi oleh petani tomat di Kelurahan Landasan Ulin Utara Kecamatan Liang Anggang Kota Banjarbaru Provinsi Kalimantan Selatan yaitu datangnya hama dan penyakit pada tanaman tomat, harga jual yang tidak tetap. Masalah diatas inilah peneliti ingin melihat dan mengamati keberadaan serta kegiatan usahatani ini, baik dari segi teknis dan dari segi ekonomis. Dalam pelaksanaannya nanti akan terlihat sejauh mana kegiatan usahatani tomat akan memberikan gambaran berapa besarnya biaya, penerimaan, pendapatan dan keuntungan petani.

Bertitik tolak dari masalah di atas serta kaitannya dengan peranan mahasiswa sebagai civitas akademis sekaligus unsur solid anggota masyarakat dianggap mempunyai, kewajiban yang cukup dalam memberikan arahan dan bimbingan pada masyarakat petani di pedesaan, dengan demikian diharapkan terjadi interaksi sosial yang positif antara mahasiswa dan masyarakat melalui praktik pengabdian pada masyarakat. Karena itu civitas akademika mempunyai peranan yang cukup besar dalam upaya ikut serta mewujudkan cita-cita bangsa diantaranya adalah pembangunan pertanian.

\section{METODE PENELITIAN}

Penelitian ini dilaksanakan di Kelurahan Landasan Ulin Utara Kecamatan Liang Anggang Kota Banjarbaru Kalimantan Selatan selama 3 bulan mulai bulan Juli 2019 - September 2019, yaitu dari tahapan persiapan sampai menyusun laporan. Data yang diperoleh kemudian diolah, selanjutnya dianalisis secara deskriptif, dan dilakukan analisis finansial (M. Subana dan Sudrajat, 2005).

Menurut Soekartawi, (2006), biaya total, yaitu keseluruhan jumlah biaya produksi yang dikeluarkan. Secara matematis biaya total dapat dirumuskan sebagai berikut:

$$
\mathbf{T C}=\mathbf{T F C}+\mathbf{T V C}
$$

Keterangan

TC $($ Total Cost $)=$ Biaya Total $(\mathrm{Rp})$

TFC $($ Total Fixed Cost $)=$ Total Biaya Tetap (Rp)

TVC $($ Total Variable Cost $)=$ Total Biaya Variabel (Rp)

Menurut Ronny (2010), penerimaan total secara langsung ditentukan oleh jumlah produk yang terjual dan yang diterima. Secara matematis penerimaan total dapat dirumuskan sebagai berikut:

$$
\mathbf{T R}=\mathbf{P} \times \mathbf{Q}
$$

Keterangan :

TR $($ Total Revenue $)=$ Penerimaan total

$\begin{array}{ll} & (\mathrm{Rp}) \\ \mathrm{P} \quad \text { (Price) } & =\text { Harga produk }(\mathrm{Rp}) \\ \mathrm{Q} \text { (Quantity) } & =\text { Jumlah produk }(\mathrm{Kg})\end{array}$

Menurut Kasim (1995), untuk menentukan tingkat pendapatan maka dianalisis secara tabulasi sederhana dengan menggunakan rumusan sebagai berikut :

$$
\mathbf{I}=\mathbf{T R}-\mathbf{T V C}
$$

Keterangan :

I $($ Total Revenue $)=$ Pendapatan Total $(\mathrm{Rp})$ TR $($ Total Revenue $)=$ Penerimaan Total (Rp) 
TVC $($ Total Variable Cost $)=$ Biaya

Variabel Total (Rp)

Menurut Sunardi dan N. Supartini. (2010), untuk menentukan tingkat keuntungan maka dianalisis secara tabulasi sederhana dengan menggunakan rumusan sebagai berikut :

$$
\boldsymbol{\pi}=\mathbf{T R}-\mathbf{T C}
$$

Keterangan :

$$
\pi \quad=\text { Keuntungan }(\mathrm{Rp})
$$

TR $($ Total Revenue $)=$ Penerimaan Total (Rp)

TVC $($ Total Cost $)=$ Biaya Total $(\mathrm{Rp})$ Adapun Kelayakan usaha secara ekonomis dapat dinilai dengan persamaan sebagai berikut (Kasmir dan Jakfar, 2008).

$$
\text { R/C Ratio }=\frac{\text { TR }}{\text { TC }}
$$

Keterangan :

TR $($ Total Revenue $)=$ Penerimaan Total (Rp)

TC $($ Total Cost $)=$ Biaya Total $(\mathrm{Rp})$

$\mathrm{R} / \mathrm{C}$ Ratio $>1$ : usaha dikatakan layak

$\mathrm{R} / \mathrm{C}$ Ratio $=1$ : usaha dikatakan berada di titik impas

R/C Ratio $<1$ : usaha dikatakan tidak layak

\section{HASIL DAN PEMBAHASAN}

Pengadaan benih tomat dilakukan dengan cara membeli yang telah siap tanam. Mutu benih yang disiapkan harus memiliki kualitas yang utuh dan sehat sehingga dapat meningkatkan produksi, mutu benih yang dipilih tidak cacat atau luka, tidak menunjukkan adanya serangan hama a tau penyakit (Wiryanta, 2002).

Benih tomat yang telah terpilih, sebelum disemaikan didesinfektan. Caranya, dengan merendam benih kedalan larutan fungisida agar mikroorganisme yang dapat menimbulkan penyakit mati. Benih dapat dilakukan dengan persemaian yaitu dengan cara menanam benih pada lubang - lubang tanam dibuat dengan jarak $10 \mathrm{~cm}$ dan kedalaman lubang tanam sekitar $1 \mathrm{~cm}$. Dan dapat diisikan 1 atau 2 benih. Setelah berumur 1 bulan baru dipindahkan ke media penanaman.

Pengolahan tanah bertujuan untuk memperbaiki struktur tanah yang gembur dan ramah. Penanaman bibit di kebun produksi harus memperhitungkan waktu, antara lain lamanya bibit di persemaian hingga dapat dipindah ditanam ke kebun dengan lamanya proses pengolahan tanah sampai siap tanam. Tahapan tahapan dalam pengolahan tanaman tomat sebagai berikut:

a. Pembentukan bedengan dapat dibuat dengan ukuran lebar $1-1,2 \mathrm{~m}$, panjang disesuai dengan keadaan lahan dan tinggi bedengan $30 \mathrm{~cm}$. b.pengemburan tanah dicangkul dengan ked alaman $23-30 \mathrm{~cm}$.

c. Pemberian kapur pada tanah yang terlalu asam dan tidak sesuai dengan persyaratan d. Pemupukan dasar dengan pupuk kandang dan diratakan di atas tanah bedengan.

Bedengan yang telah dipersiapkan untuk penanaman bibit, sehari sebelumnya hendaknya diairi terlebih dahulu supaya basah. Kemudian bedeng dibuat lubang tanam dengan diameter $15-20 \mathrm{~cm}$ sedalam $\quad 17 \quad \mathrm{~cm}$. Lubang-lubang tanam dibuat sesuai dengan jarak tanam yan $\mathrm{g}$ telah ditentukan.

Penanaman dapat dilakukan pada lubang yang sudah diberi pupuk dengan kedalaman lubang $15 \mathrm{~cm}$ dengan jumlah bibit per lubang tanam sebanyak 1 bibit $\mathrm{cm}$. Pemeliharaan yang diperlukan tanaman tomat meliputi penyiraman, penyulaman, pengajiran, pemupukan, pemangkasan, penyiangan dan pengendalian hama dan penyakit.

Penyiraman dilakukan pada pagi dan sore hari, apabila keadaan cuaca menjadi sangat panas. Tujuan penyiraman untuk mengantikan air yang telah menguap pada siang hari, memberi tambahan air yang dibutuhkan oleh tanaman, dan mengembalikan kekuatan tanaman.

Penyulaman adalah mengganti tanaman yang mati, rusak atau yang 
pertumbuhannya tidak normal, misalnya tumbuh kerdil. Penyulaman sebaiknya dilakukan seminggu setelah tanam. Namun jika satu minggu sudah terlihat adanya tanaman yang mati, layu, rusak atau pertumbuhannya tidak normal, penyulaman sebaiknya segera dilakukan. Untuk penyulaman mengunakan bibit cadangan yang telah dipersiapkan terlebih dulu.

Tanaman tomat mempunyai batang yang kurang kuat untuk menopang buah dan mendukung tegaknya batang. Oleh karena itu, diperlukan ajir untuk menopangnya. Selain itu, juga berguna untuk memudahkan dalam pemeliharaan dan pemetikan buahnya. Ajir bisa dibuat dari bilah bambu dengan lebar 2-3 cm dan panjang $1 \mathrm{~m}$. Bagian bawah ajir dibuat runcing agar mudah ditancapkan. Tancapkan ajir di dekat batang tomat. Ujung ajir dapat dibiarkan tegak atau dapat juga dimiringkan dan ujungnya disatukan dengan ujung ajir yang lain. Kemudian batang tomat diikat pada ajir dengan tali rafia. Ikatan diatur sedemikian rupa sehingga tidak terlalu erat atau kendur. Pemberian ajir dilakukan 3-4 minggu setelah panen. Untuk biaya ajir Rp 400,-/batang dan tali raffia $\mathrm{Rp} 7000,-/ \mathrm{kg}$.

Tomat dapat tumbuh sehat jika tanah tempat tumbuhnya cukup tersedia hara makro dan mikro. Pupuk yang digunakan adalah pupuk kandang, Ponska, NPK dan SP daun KCL dengan perbandingan $1: 1$. Cara pemberian pupuk ada 2 macam, yaitu sebagai berikut:

-Pemupukan dilakukan di sekeliling tanaman pada jarak $\pm 3 \mathrm{~cm}$ dari batang tanaman tomat kemudian pupuk ditutup tanah dan disiram dengan air. Pemupukan ini dilakukan pada saat tanaman berumur 1 minggu setelah tanam dengan dosis 1 2 gr.

- Pemupukan dilakukan disekeliling batang tanaman sejauh $\pm 5 \mathrm{~cm}$ dan dalamnya $\pm 1 \mathrm{~cm}$ kemudian pupuk ditanah dan disiram dengan air. Pemupukan ini dilakukan pada saat tanam berumur $2-3$ minggu dengan dosis 5 gr.
Pemangkasan untuk mengurangi jumlah tunas dan pucuk batang sehingga perkembangan buahnya maksimal. Selain itu untuk mengurangi gangguan hama dan penyakit.

Penyiangan untuk mencabut tanaman liar atau bisa juga menggunakan alat untuk mencabutnya. Kegiatan ini diulangi 3 minggu kemudian, yaitu saat tomat mulai berbunga. Penyiangan harus dilakukan dengan hati-hati agar tidak banyak.Akar yang terpotong dapat menyeba bkan batang menjadi layu atau

buah muda gugur. Waktu penyiangan dilakukan $3-4$ kali tergantung kondisi lahan.

Upaya pengendalian tanaman tomat $\mathrm{s}$ ecara preventif dengan menggunakan Antracol, Gion M, Scor, Bom Blower, Prepature secara intensif. Aplikasi penyemprotan dilakukan sebanyak $21-25$ kali per musim tanam, dengan konsentrasi di atas anjuran. Hama yang menyerang tanaman ini adalah ulat buah (Helicoperva armigera dan Heliotis sp). Gejala buah berlubang dan kotoran menumpuk dalam buah yang terserang. Penyakit yang menyerang tanaman tomat adalah busuk daun (Phytopthora infestans), bercak daun dan buah Alternaria solani serta busuk buah Antraknose (Colletotricum coccodes).

Panen pada umur 90-100 hari setelah tanam dengan ciri-ciri kulit buah berubah dari warna hijau menjadi kekuningkuningan, bagian tepi daun tua mengering, batang menguning, pada pagi atau sore hari disaat cuaca cerah. Pemetikan 2-3 hari sekali, buah dipuntir hingga tangkai buah terputus. Pemuntiran buah dilakukan satupersatu dan dipilih buah yang siap petik. Supaya buah tahan lama, tidak cepat busuk dan tidak mudah memar, buah tomat yang akan dikonsumsi segar dipanen setengah matang. Wadah yang baik untuk pengangkutan adalah peti-peti kayu dengan papan bercelah dan jangan dibanting. Waspada penyakit busuk buah Antraknose, kumpulkan dan musnahkan buah tomat yang 
telah dipetik. Bersihkan, disortasi dan dipacking lalu diangkat siap untuk dikonsumsi.

Komponen biaya yang dihitung dan dianalisis pada usahatani tomat selama 1 (satu) kali musim tanam, yaitu 3 (tiga) bulan, meliputi biaya sarana produksi, biaya alat perlengkapan dan pajak lahan serta biaya tenaga kerja.

\section{Biaya sarana Produksi}

Untuk lebih jelasnya mengenai biaya sarana produksi pada usahatani tomat dapat dilihat pada Tabel 1 berikut.

Tabel 1. Rata-rata Biaya Sarana Produksi Usahatani Tomat di Kelurahan Landasan Ulin Utara.

\begin{tabular}{llrc}
\hline No & \multicolumn{1}{c}{ Uraian } & Biaya $(\mathrm{Rp})$ & Persentasi $(\%)$ \\
\hline 1 & Benih & $7.463 .000,00$ & 26,3 \\
2 & Pupuk & $15.439 .447,33$ & 54,5 \\
3 & Obat-obatan & $5.442 .666,67$ & 19,2 \\
\hline & Jumlah & $28.345 .114,00$ & 100,0
\end{tabular}

Sumber : Hasil Pengolahan Data Primer Tahun 2019

Biaya sarana produksi yang dikeluarkan dihitung dengan mengalikan jumlah input produksi yang digunakan dengan harga masing-masing input. Biaya sarana produksi meliputi keperluan benih rata-rata sebesar Rp. 7.463.000,00 per petani, pupuk rata-rata sebesar $\mathrm{Rp}$. 15.439.447,33 per petani dan obat-obatan rata-rata sebesar Rp. 5.442.666,67 per petani. Persentase besarnya biaya benih petani $26,3 \%$ biaya pupuk $54,5 \%$ dan untuk biaya obat-obatan 19,2\% .

\section{Biaya Penyusutan Alat}

Sehubungan dengan berkurangnya nilai pakai alat-alat produksi pertanian, maka dapat diadakan perhitungan biaya penyusutan alat-alat tahan lama yang mengandung sejumlah nilai pakai yang harus diperhitungkan setiap tahunnya. Biaya penyusutan ini tergantung pada nilai alat saat pembeliaan, usia ekonomis alat, nilai sisa setelah habis jangka ekonomis tersebut (dalam hal ini dianggap nol) dan masa kerja efektif alat pada usahatani tomat.

Tabel 2. Rata-rata Biaya Penyusutan Alat Pada Usahatani Tomat di Kelurahan Landasan Ulin Utara.

\begin{tabular}{llrc}
\hline No & \multicolumn{1}{c}{ Uraian } & Biaya (Rp) & Persentasi (\%) \\
\hline 1 & Cangkul & $6.327,44$ & 0,11 \\
2 & Parang & $2.529,67$ & 0,04 \\
3 & Semprotan & $21.442,42$ & 0.37 \\
4 & Mulsa Hp & $3.258 .194,15$ & 56,50 \\
5 & Ajir & $2.462 .538,67$ & 42,70 \\
6 & Tali raffia & $16.267,26$ & 0,28 \\
\hline & Jumlah & $5.767 .229,61$ & 100,00 \\
\hline
\end{tabular}

Sumber : Pengolahan Data Primer 2019

Berdasarkan data pada Tabel 2 diketahui biaya penyusutan alat terbesar pada penggunaan Mulsa Hp yaitu sebesar Rp. $3.258 .194,15$ per petani $(56,50 \%)$ sedangkan yang terkecil pengunaan pada parang $2.529,67$ per petani $(0.04 \%)$.

\section{Biaya tenaga Kerja Luar Keluarga}

Dalam kegiatan usahatani tomat yang dilaksanakan petani selama satu kali musim tanam, tenaga kerja luar keluarga yang meliputi pengolahan tanah, penanaman dan panen. 


\section{Pajak Lahan}

Pajak lahan tergantung luas lahan yang dimiliki petani serta masa produksinya. Pajak lahan yang berlaku pada saat pengamatan 60.000, /ha/tahun. Berdasarkan hasil perhitungan di atas biaya rata-rata pajak lahan pada usahatani tomat di Kelurahan Landasan Ulin Utara sebesar Rp. $18.540,33,-/$ petani.

\section{Biaya Eksplisit}

Biaya eksplisit adalah biaya keseluruhan biaya yang dikeluarkan dalam satu musim tanam. Biaya ini meliputi penyusutan alat, pajak lahan, TKLK, dan saprodi. Untuk lebih jelasnya dapat dilihat pada Tabel 3.

Tabel 3. Biaya Eksplisit Rata-rata yang dikeluatkan pada Usahatani Tomat di Kelurahan Landasan Ulin Utara.

\begin{tabular}{llcc}
\hline No & \multicolumn{1}{c}{ Uraian } & Biaya $(\mathrm{Rp})$ & Persentasi $(\%)$ \\
\hline 1 & Penyusutan alat & $5.767 .229,61$ & 13,90 \\
2 & Pajak lahan & $18.540,33$ & 0,05 \\
3 & Saprodi & $28.345 .114,00$ & 68,33 \\
4 & TKLK & $7.350 .457,67$ & 17,72 \\
\hline & Jumlah & $41.481 .341,61$ & 100,00 \\
\hline
\end{tabular}

Sumber : Pengolahan Data Primer 2019

Dari Tabel 3 diketahui, penggunaan biaya tertingi dan terendah pada petani yaitu biaya tertinggi pada saprodi sebesar $\mathrm{Rp}$. 28.345.114,00 (68,33\%) sedangkan biaya penggunaan terandah pada pajak lahan yaitu sebesar Rp. 18.540,33 (0,05\%).

\section{Biaya Implisit}

\section{Biaya Tenaga Kerja Dalam Keluarga}

Penggunaan Tenaga Kerja Dalam

Keluarga (TKDK) meliputi penyiraman, penyemprotan, pemupukan dan penyiangan. Besar tenaga kerja dalam keluarga oleh petani kurang di perhatikan, khususnya mengenai upah yang diberikan. Walaupun petani tidak meupah secara langsung untuk penggunaan tenaga kerja dalam keluarga sendiri, tetapi dalam perhitungan suatu usahatani upah tersebut tetap diperhitungkan. Rata-rata biaya dalam penyelenggaraan tenaga kerja dalam keluarga sebesar Rp. 9.326.521,67/petani.

\section{Bunga Modal}

Bunga modal diperhitungkan dan dimasukkan dalam biaya implisit, karena Modal yang digunakan adalah milik petani sendiri. Perhitungan bunga modal adalah dengan jalan mengalikan antara total biaya eksplisit yang dikeluarkan petani dengan besarnya bunga modal (tingkat suku bunga) yang berlaku saat itu, biasanya bunga modal mengikuti tingkat suku bunga pada Bank/KUD yang telah di sepakati (18\%/tahun) untuk tanaman tomat hanya 3 bulan dari tanam sampai panen jadi bunga modal $4,5 \%$ per 3 Bulan, sehingga di peroleh rata-rata bunga modal yang di keluarkan petani sebesar Rp. 1.866.660,37/petani. Data dapat dilihat pada Tabel 4

Tabel 4. Biaya Implisit Rata-rata yang dikeluarkan pada Usahatani Tomat di Kelurahan Landasan Ulin Utara.

\begin{tabular}{llcc}
\hline No & \multicolumn{1}{c}{ Uraian } & Biaya (Rp) & Persentasi (\%) \\
\hline 1 & TKDK & $9.326 .521,67$ & 84,59 \\
2 & Bunga Modal & $1.866 .660,37$ & 15,41 \\
\hline & Jumlah & $11.193 .182,04$ & 100,00 \\
\hline
\end{tabular}

Sumber : Pengolahan Data Primer 2019 
Dari Tabel 4 diketahui, penggunaan biaya TKDK sebesar Rp. 9.326.521,67 $(84,59 \%)$ sedangkan biaya bunga modal yaitu sebesar Rp. 1.866.660,37 (15,41\%).

\section{Biaya Total}

Biaya total adalah hasil dari nilai tambahan biaya eksplisit dan biaya implisit dari penyelenggaraan usahatani tomat.

Tabel 5. Biaya Total Rata-rata yang dikeluarkan petani pada Usahatani Tomat di Kelurahan Landasan Ulin Utara.

\begin{tabular}{clcc}
\hline No & \multicolumn{1}{c}{ Uraian } & Biaya $(\mathrm{Rp})$ & Persentasi (\%) \\
\hline 1 & Total Biaya Eksplisit & $41.481 .341,61$ & 78,75 \\
2 & Total Biaya Implisit & $11.193 .182,04$ & 21,25 \\
\hline \multicolumn{2}{l}{ Jumlah } & $52.674 .523,65$ & 100,00 \\
\hline
\end{tabular}

Sumber : Pengolahan Data Primer 2019

Dari Tabel 5 diketahui, penggunaan biaya Total Biaya Eksplisit sebesar Rp. 41.481.341,61 (78,75\%) sedangkan Total Biaya Implisit yaitu sebesar Rp. 11.193.182,04 (21,25\%). Sehingga biaya total yang digunakan dalam usahatani tomat adalah rata-rata $\mathrm{Rp}$. 52.674.523,65/petani.

\section{Penerimaan}

Penerimaan adalah perkalian antara total produksi dengan harga yang berlaku pada saat itu, dari hasil wawancara dengan seluruh petani responden diperoleh total rata-rata produksinya adalah sebesar $23.482,43 \mathrm{Kg} /$ petani dengan harga tomat $\mathrm{Rp}$. $4.000 / \mathrm{kg}$. Sehingga total penerimaan ratarata adalah Rp. 93.929.720/petani.

Pada penelitian kelayakan usahatani tomat di Kabupaten Jember Provinsi Jawa Timur diketahui bahwa nilai produksi sebesar Rp. 1.004.200 kg dengan rata-rata sebesar 16.736,67 kg/petani dari 60 orang responden sedangkan Produksi yang diperoleh dari usahatani tomat di Kelurahan Landasan Ulin Utara dari 15 petani responden adalah $352.236,45 \mathrm{~kg}$ dengan rata-rata sebesar 23.482,43 kg/petani (Bagus Rangga Sita, Syamsul Hadi, 2016).

\section{Pendapatan}

Pendapatan adalah hasil pengurangan antara total penerimaan dengan total biaya eksplisit yang dikeluarkan petani dalam satu musim tanam. pendapatan yang di peroleh petani dalam satu musim tanam adalah Ratarata sebesar Rp. 52.448.378,39/petani. Pendapatan masih dapat ditingkatkan dengan mempelajari situasi pasar dan system pemasaran agar memperoleh harga yang memadai. Agar tingkat pendapatan meningkat perlu adanya peningkatan peningkatan efesiensi biaya dan peningkatan penerimaan (TR) melalui peningkatan hasil produksi. Hal ini bisa dilaksanakan apabila petani mengetahui penggunaan hubungan antara input dan output. Semakin optimal penggunaan input produksi diharapkan output bisa lebih maksimal.

\section{Keuntungan}

Keuntungan adalah antara selisih penerimaan total dengan total biaya yang dikeluarkan oleh petani dalam satu kali musim tanam. Keuntungan total yang diperoleh rata-rata sebesar $\mathrm{Rp}$. 41.255.196,35/petani.

Sesuai dengan kondisi petani tomat di Kelurahan Landasan Ulin Utara secara umum memiliki permasalahan yang sama dalam membudidayakan tomat. Diantaranya minimnya modal yang dimiliki petani, kurangnya pengetahuan petani tentang budidaya tanaman tomat. Dalam kondisi seperti ini petani tomat sangat memerlukan informasi dan penyuluhan dari petugas lapangan dan instansi teknis terkait. Keuntungan akan meningkat apabila jumlah biaya yang dikeluarkan cukup kecil/berkurang. Bila terjadi penekanan biaya dengan di asumsikan harga tomat masih stabil (baik). Begitu juga sebaliknya jumlah keuntungan akan semakin rendah apabila penggunaan biaya cukup tinggi. 


\section{Kelayakan}

Revenue cost ratio (RCR) adalah ratio yang digunakan untuk melihat keuntungan relatif yang akan didapatkan dalam sebuah usaha. Sebuah usaha layak untuk dijalankan apabila nilai RCR yang didapatkan lebih besar daripada 1, sebaliknya bila usaha layak untuk dijalankan apabila nilai RCR yang didapatkan kurang daripada 1. Nilai RCR didapat dengan membandingkan nilai penerimaan dengan total biaya usahatani tomat. Untuk usahatani tomat didapat total penerimaan rata-rata adalah Rp. 93.929.720/petani dan biaya total yang digunakan dalam usahatani tomat adalah rata-rata $\mathrm{Rp}$. 52.674.523,65/petani. Sehingga didapat nilai RCR adalah 1.78. Nilai RCR usahatani tomat yang lebih besar dari 1 dapat disimpulkan usahatani tomat di Kelurahan Landasan Ulin Utara layak untuk dijalankan.

Pada penelitian kelayakan usahatani tomat di Kelurahan Boyaoge Kecamatan Tatanga Kota Palu Provinsi Sulawesi Tengah diketahui bahwa nilai pendapatan sebesar Rp. 17.483.225/ha dengan nilai RCR sebesar 1.76 dengan jumlah responden 35 orang petani tomat. Nilai RCR usahatani tomat di Kelurahan Landasan Ulin Utara Kota Banjarbaru lebih tinggi yaitu 1,78 (Saddam Fadli, 2014).

Pada penelitian kelayakan usahatani tomat di Desa Gading Kulon Kecamatan Dau Kabupaten Malang Provinsi Jawa Timur diketahui bahwa nilai pendapatan sebesar Rp. 82.822.883/ha dengan nilai RCR sebesar 1.74. Dengan nilai RCR $>1$ maka usahatani tomat di Desa Gading Kulon Kecamatan Dau Kabupaten Malang layak diusahakan. Nilai RCR usahatani tomat di Kelurahan Landasan Ulin Utara Kota Banjarbaru lebih tinggi yaitu 1,78 (Aloysius Rabha Gempa, Eri Yusnita, Said Masduki, 2017).

Pada penelitian kelayakan usahatani tomat diantara pertanaman kelapa di Kabupaten Sangihe Provinsi Sulawesi Utara diketahui bahwa nilai pendapatan sebesar
Rp. 10.690.000/0.3 ha, dengan sistem semi intensif penerimaan sebesar 14.840.000/0.2 ha dengan nilai RCR sebesar 4.36. Dengan nilai $\mathrm{RCR}>1$ maka usahatani tomat di Kabupaten Sangihe Provinsi Sulawesi Utara layak diusahakan. Tingginya Nilai RCR usahatani tomat di Kabupaten Sangihe Provinsi Sulawesi Utara yaitu 4,36 dibanding Nilai RCR usahatani tomat di Kelurahan Landasan Ulin Utara Kota Banjarbaru 1 yaitu 1,78 disebabkan penggunaan sistem semi intensif yaitu penanaman tomat diantara pertanaman kelapa. Hal ini perlu di aplikasikan oleh petani tomat di Kelurahan Landasan Ulin Utara Kota Banjarbaru sebagai nilai kebaharuan dimana penggunaan sistem semi intensif yaitu penanaman tomat diantara pertanaman kelapa belum pernah di aplikasikan di lokasi penelitian (Jantje G. Kindangen, Payung Layuk, 2015).

Pada penelitian kelayakan usahatani tomat di Desa Gunung Intan Kecamatan Babulu Darat Kabupaten Penajam Paser Utara Provinsi Kalimantan Timur diketahui bahwa nilai pendapatan sebesar Rp. 55.419.840/ha dengan nilai RCR sebesar 2.84. Dengan nilai RCR $>1$ maka usahatani tomat di Desa Gunung Intan Kecamatan Babulu Darat layak diusahakan. Nilai RCR usahatani tomat di Kelurahan Landasan Ulin Utara Kota Banjarbaru lebih rendah yaitu 1,78 (Bilkis, dkk. 2014).

\section{KESIMPULAN DAN SARAN}

Berdasarkan hasil penelitian terhadap usaha ternak ayam broiler, maka dapat diambil beberapa kesimpulan sebagai berikut :

1. Dilihat dari teknis penyelenggaraan usahatani tomatyang diterapkan di Kelurahan Landasan Ulin Utara masih relatif sederhana, ini terlihat dari pengolahan lahan sampai pemeliharaan.

2. Produksi yang diperoleh dari usahatani tomat di Kelurahan Landasan Ulin Utara dari 15 petani 
responden adalah $352.236,45 \mathrm{~kg}$ dengan rata-rata sebesar 23.482,43 $\mathrm{kg} /$ petani. Total Penerimaan rata-rata Rp. 93.929.720 per petani . Total Pendapatan rata-rata Rp. 49.463.569,44 per petani. Total Keuntungan rata-rata yang di peroleh pada usahatani tomat di Kelurahan Landasan Ulin Utara sebesar Rp. 41.255.196,35/petani.

3. Nilai RCR usahatani tomat di Kelurahan Landasan Ulin Utara adalah 1.78 sehingga layak untuk diusahakan.

\section{Saran}

Untuk meningkatkan keberhasilan usaha tanaman tomat di Kelurahan Landasan Ulin Utara perlu dilakukan perbaikan sumber daya manusia melalui peningkatan keterampilan petani, perbaikan penyelenggaraan usahatani, penyediaan sarana produksi dan penggunaannya yang sesuai anjuran, penggunaan tenaga kerja yang optimal melaui peningkatan kemampuan petani dalam penyelenggaraan usahatani tanaman tomat. Khusus untuk pemeliharaan tanaman, dimana petani dalam penggunaan pupuk belum sesuai dengan anjuran begitu juga penggunaan benih tidak menggunakan varietas unggul.

\section{DAFTAR PUSTAKA}

Aloysius Rabha Gempa, Eri Yusnita, Said Masduki, 2017. Kelayakan Usahatani Tomat di Desa Gading Kulon Kecamatan Dau Kabupaten Malang Provinsi Jawa Timur. Jurnal Fakultas Pertanian Vol.5 No.2 Universitas Tribhuwana Tunggadewi Jawa Timur

Bagus Rangga Sita, Syamsul Hadi. 2016. Produktivitas dan Faktor-Faktor Yang Berpengaruh Terhadap Produksi Usahatani Tomat Di Kabupaten Jember. Jurnal JSEP Vol. 9 No.3 November 2016.
Faperta Universitas Jember Jawa Timur.

Cahyono, 1998. Tomat : Usahatani dan Penanganan Pasca Panen. Kanisius. Yogyakarta

Jantje G. Kindangen, Payung Layuk, 2015. Kelayakan Usahatani Tomat Diantara Pertanaman Kelapa. Buletin Palma Vol.16 No.1. Balitka Sulawesi Utara

Kasmir dan Jakfar, 2008. Studi Kelayakan Agribisnis. Kencana Prenada Media Group. Jakarta.

M. subana dan sudrajat, 2005. Dasar Dasar Penelitian Ilmiah.

Patricia, 2001. Analisis Pendapatan Usahatani Tomat. Skripsi Fakultas Pertanian UNSRAT Manado.

Ronny, 2010. Pendapatan Usahatai Campuran. Seminar hasil Penelitian Fakultas Pertaniaan UNSRAT Manado.

Saddam Fadli, 2014. Kelayakan Usahatani Tomat di Kelurahan Boyaoge Kecamatan Tatanga Kota Palu Provinsi Sulawesi. Jurnal Agroland Vol.21 No.1. Fakultas Pertanian Universitas Tadulako Sulawesi Tengah.

Siti Bilkis, Muhammad Najib, Elis Siti Masitoh. 2014. Analisis Usahatani dan Pemasaran Tomat Di Desa Gunung Intan Kecamatan Babulu Darat Kabupaten Penajam Paser Utara Provinsi Kalimantan Timur. Jurnal Dinamika Pertanian Vol.29 No. 2 Agustus 2014. Universitas Mulawarman Samarinda. 
Soekartawi, 2006. Analisis Usahatani. Universitas Indonesia, Jakarta.

Soenoeadji, 2001. Pengantar Ilmu Pertanian Holtikultura. Universitas Gajah Mada,Yogyakarta

Suratiyah, 2006. Ilmu Usahatani, Penebar swadaya. Jakarta
Syarifuddin A. Kasim 1995. Pengantar Ekonomi Produksi Pertanian Universitas Lambung Mangkurat Banjarbaru.

Wiryanta, 2002. Bertanam Tomat, PT Agromedia Pustaka, Jakarta 